\title{
Assessment of pediatric nurses' performance regarding intravenous Therapy
}

\author{
Nagwa Ibrahim Mohamed (1), Sanaa Mahmoud Ahmed (2), Asmaa Hamed Tawfic (3) \\ 1. Bsc.inNursing,FacultyofNursing,MiniaUniversity \\ 2. Assistant Professor of Pediatric Nursing, Faculty of Nursing- Minia University \\ 3. Lecturer of Pediatric Nursing, Faculty of Nursing Minia University-MiniaUniversity
}

\begin{abstract}
Background: Intravenous therapy is an important part of the treatment of many hospitalized patients. Fluid and electrolyte therapy is an essential component of the care of hospitalized children. The aim of this study is to assess pediatric nurses' performance regarding intravenous therapy in Minia University hospital and Minia General Hospital. Design: Descriptive research design was used for this study. Setting: This study was conducted at Minia University for Pediatrics and Obstetrics Hospital and Minia General Hospital affiliated to the Ministry of health and population. Subjects: A convenient sample consisting of 58 nurses who were divided into 29 nurses from the pediatric and emergency department at Minia University Pediatrics and Obstetrics Hospital as well as 29 nurses from the pediatric and emergency department at Minia General Hospital over six months were included. Tools of data collection: Three tools were included for data collection; Tool I: A structured interview questionnaire sheet in an Arabic language. It consisted of two parts: Part 1: personal data of nurses as age, qualifications, years of experience, and previous training courses. Part 2: Knowledge assessment sheet: it contained 30 close-ended questions to assess nurse's knowledge about nursing care regarding insertion, maintenance, and removal of the intravenous line. Tool II: Observational checklist sheet was developed by the researcher to assess the nurses' practices for intravenous therapy it contained 12 procedures (149 steps) Tool III: Nurses' attitude regarding intravenous therapy. More than half of nurses in Minia University Hospital (MUH) and 44.8\% of them in Minia General Hospital (MGH) had incomplete knowledge regarding intravenous therapy with high statistical significance differences P-value .006. Also, more than two-thirds of nurses in MUH and 51.7\% of them in MGH had incomplete practice regarding intravenous therapy with no statistical significance differences P-value .117. Conclusion: These results concluded that one third of nurses worked in Minia University Hospital had very good knowledge and 10.3\% of them had complete practice than a few of nurses worked in Minia General hospital but more than three quarters of nurses in Minia general hospital had positive attitude regarding intravenous therapy with statistically significant difference which P-value 0.04 . Recommendations The education program should be applied and repeated every 3 months in the same study setting and adopted in other similar settings with necessary modifications, the provision of continuing education programs is suggested regularly to refresh and update the knowledge of nurses, as well as to reinforce appropriate practices in pediatric units related to intravenous therapy with continuous supervision.
\end{abstract}

Keywords: Pediatric Nurses, Nurses' Performance, Intravenous Therapy

\section{Introduction}

Intravenous therapy (IV) is an important part of the treatment of many hospitalized patients. IV solutions are medications. Administration of medications is part of the controlled acts authorized to nursing. It is the nurse's responsibility to ensure that the patient receives the ordered solution and additives at the ordered rate. The extravasation of any IV fluid can cause serious permanent harm. Hourly checks are to identify extravasation early (Hoste et al., 2014).

Intravenous solutions often have similar packaging; therefore, great care is required in selecting the right intravenous solution. Particular care is required if the patient has more than one IV line or pump to ensure that lines are not mixed up. When an IV bag is changed or if medications are being added to one of the lines, the line must be tracked right back to the solution container to verify that the additive is being added to the correct line (Palomo et al., 2015).

Intravenous infiltration can lead to problems like discomfort, the need for reinsertion of the intravenous catheters which associated with pain and anxiety from repetitive failed (PIV ) insertion attempts, or compartment syndrome, which can increase not only the period of hospitalization and medical expenses for treatment but also permanent damage in children. These problems can lead to prolonged hospitalization, increased medical costs, higher mortality, and greater morbidity (Flippo \& Lee, 2011).
Nurses play a vital role in the administration of intravenous therapy. Most of the interventions and prevention strategies such as insertion, monitoring and assessing peripheral venous catheter (PVC) sites are part of routine nursing care. Nurses should have accurate knowledge of the preparation and administration of the IV Infusion and IV device. In addition, they should also know about the prevention, treatment, and management of local and systematic complications supported by dynamic evidence-based practice guidelines. One of the major risks for phlebitis incidence is due to the placement and maintenance of PVC by insufficiently trained staff (Mohammed \& Ahmed, 2017).

\section{Significance of the study}

Peripheral intravenous (PIV) therapy is one of the most frequently used therapeutic interventions in the acute care setting. In the acute care pediatric setting, starting and monitoring intravenous (IV) therapy is challenging and poses a significant risk to small infants and children (De Lima Jacinto, et al., 2011), (Walsh \&Schad, 2012).

A vein cannula has direct access to the patient vascular system and is a potential route for micro-organisms to enter bypassing the skin and in connection with drugs and /or fluids given. Despite this factual information, Studies indicated that nurses do not regularly assess the peripheral intravenous cannula and are frequently unaware of complications (Zhang et al, 2016). Peripheral intravascular (PIV) complications were reported 
at rates as high As $28 \%$ in children compared to $8.5 \%$ in adults. Furthermore, infants and children pose challenges to optimal PIV management because of their limited communication abilities, unpredictable behavior and activity levels, and small vessel sizes (Flippo \& Lee, 2011)

Children are particularly vulnerable to these PIVinduced complications. Several studies have suggested that a dedicated IV therapy team may reduce catheter-related complications by standardizing catheter insertion technique, inspecting catheter sites daily, and rotating catheter sites within 72 hours of placement (CDC 2013).

\section{Aim of the study}

This study aimed to

Assess pediatric nurses' performance regarding intravenous therapy at Minia University Hospital and Minia General Hospital.

\section{Research questions}

- What is the nurses' performance as regards insertion, maintenance, and removal of intravenous line to children in Minia university hospital and general hospital?

- What are the differences between pediatric nurses' performance at Minia University Hospital and Minia General Hospital?

\section{Research Design}

The descriptive study design was used for this study

\section{Setting:}

This study was conducted in pediatric and emergency departments at Minia University for Pediatrics and Obstetrics Hospital and Minia General Hospital affiliated to the Ministry of health and population.

\section{Subjects}

A convenient sample consisting of 58 nurses (29 of nurses were from the pediatric and emergency departments in Minia University for Pediatrics and Obstetrics Hospital and 29 of them were from the pediatric and emergency departments at Minia General Hospital and over six months.

\section{Data Collection Tools \\ Three tools were included for data collection}

Tool I

A structured interview questionnaire sheet in the Arabic language to gather data of the studied sample and designed by the investigator after an extensive review of related literature and the consultation of the experts in the field of pediatrics and pediatric nursing.

\section{It consisted of two parts}

- Part 1: Personal data of nurses: it contained 4 items of selected personal items about nurses as age, qualifications, years of experience, and previous training courses.

- $\quad$ Part 2: Knowledge assessment sheet: it contained 30 questions. Questions in form of close-ended to assess nurse's knowledge about nursing care as regards insertion, maintenance, and removal of the intravenous line to children and the different intravenous therapy complication which might occur to children.
Scoring system of nurses' knowledge:

Scoring system for knowledge of the studied nurses was calculated as the following:

All knowledge variables were weighted as (2) for the complete correct answer and (1) for an incomplete correct answer and, (0) for choosing don't know or incorrect answer. The total score of nurses' knowledge was 60.

The nurses' total knowledge score was classified as the following:

- Very good: $(\geq 75 \%)$

- Good: $(50-<75 \%)$

- Poor: $(<50 \%)$.

\section{Tool II}

Observational checklist sheet was developed by the researcher that was adopted from Terese and Marlene,(2010), Patricia and Anne,(2008) to assess the nurses' practices for intravenous therapy it contained 12 procedures (149 steps) as infection control (10 steps), hand washing (19 steps), wear personal protective gloves (32 steps), insertion I.V cannulation (16 steps), removal I.V cannulation (9 steps), I.V fluid preparation (9 steps), administration of I.V fluid drug infusions (7 steps), administration of blood products (7 steps), flushing of PIVC's (9 steps), IV fluid considerations via peripheral IV line (12 steps), change of PIVC dressing and securing of cannula (11 steps), and management of I.V therapy complications (8 steps).

\section{Scoring system of nurses' practice}

Scoring system for practicing nursing care was calculated as the following:

Performances step was weighted as 0 for not done, 1 for incomplete done, and 2 for completely done. The total score of nurses' practice was 298.

\section{The nurses' total practice score was classified as: \\ - Complete: $(\geq 75 \%)$ \\ - Incomplete: $(50-<75 \%)$ \\ - Not done: $(<50 \%)$.}

Tool III

Nurses' attitudes regarding intravenous therapy: it contained 10 items by using the Likert scale includes three points as agree, uncertain, and disagree. Their attitude as the first line of nursing management for intravenous therapy, wear gloves is the first step in the insertion of the cannula, if intravenous cannula inserted incorrectly, removed it and try again, etc.

\section{Scoring system of nurses' attitude}

Scoring system Nurses' attitude regarding intravenous therapy was calculated as the following:

All attitude variables were weighted as $(0)$ score for disagree, (1) score for uncertain, and (2) score for agreeing. The total score of the nurses' attitude was 20 .

The nurses' total attitude score was classified as the following:

- $\quad$ Positive: $>60 \%$

- Negative: $\leq 60 \%$ 


\section{Validity and Reliability}

The content validity of the data collection tool was examined by five experts who were affiliated to the Faculty of Nursing, Minia, and Assuit University at the Pediatric Nursing Department. The tool was examined for content coverage, clarity, relevance, applicability, wording, length, format, and overall appearance. Based on experts' comments and recommendations; minor modifications had been made such as rephrasing and rearrangements of some sentences.

Internal consistency was measured to identify the extent to which the items of tools measure the same concept and correlated with each other. Internal consistency estimate reliability by grouping questions in the questionnaire that measure the same concept. Cronbach's alpha for reliability testing internal consistency was performed for each section of the structured interview questionnaire and the results were $0.750,985$, and 0.70 for nurses' knowledge, practice, and attitude regarding intravenous therapy respectively.

\section{Pilot study}

Random selection of $10 \%$ (5 nurses) of the total number of nurses to investigate and ensure the feasibility, objectivity, applicability, clarity, adequacy, and to determine possible problems in the methodological approach or instrument. The results of the pilot study were used to test the proposed statistical and data analysis methods. The tools were completed without difficulty, adding support to the validity of the instrument. Little modification was done e.g. rephrasing and rearrangements of some sentences. The time required for completion of the interview questionnaire didn't exceed 30 minutes. Nurses involved in the pilot study were included in the main study sample. Pilot testing helped the investigator plan for data collection.

\section{Ethical consideration}

For ethical consideration, and approval was obtained from the faculty of the nursing ethical committee and official permission was obtained from the director of the Minia University for Pediatrics and Obstetrics Hospital and Minia General Hospital, and permission from the head of pediatric and emergency departments after explaining the aim and nature of the study. Nurses' were interviewed on an individual basis to explain the nature and purpose of the study.

Oral informed consent was obtained by the researcher from the nurses before data collection after full explanation for the aim of the study, benefits, and rights for privacy. They also informed that the information obtained will be confidential and will be used be only for the study. Each assessment sheet was coded and nurses' names didn't appear on the sheets for anonymity and confidentiality.

\section{Data Collection Procedure}

Administrative approval was obtained from the ethics committee, faculty of nursing, Minia University. Official permission was obtained from the concerned hospital authorities to conduct the study after explaining the aim and nature of the study. The researcher was interviewing with nurses. At that time, the purpose and nature of the study were explained by the researcher through direct personal communication before starting to participate in the study and then the data collection.

Nurses' knowledge, practice, and attitude regarding intravenous therapy were assessed by using the structured interview questionnaire and observational checklist. The interview took place in the pediatric and emergency departments at Minia University for Pediatrics and Obstetrics Hospital and Minia General Hospital. The interview conducted for all nurses to fill the personal data and to assess their knowledge regarding intravenous therapy by using a structured interview questionnaire. The time taken to conduct the structured interview questionnaire for each nurse was ranged from 20 to 30 minutes and nurses' practice done by the observational checklist and consumed 30- 45 minutes at a rate of 3 to 5 nurses/ week. Data collection was conducted over six months extending from May 2019 up to October 2019.

\section{Statistical analysis}

The collected data were tabulated \& statistically analyzed using the software program and statistical package for social science (IBM SPSS 25.0) to evaluate nurses under study. The statistical analysis included percentage (\%), mean, stander deviation (SD) and Chi-square $\left(\mathrm{x}^{2}\right)$.Chi-square $\left(\mathrm{x}^{2}\right)$ was used to test the association between two qualitative variables. Fisher's exact test used to test the association between two qualitative variables and the sample size is small. Quantitative continuous data were compared by using a t-test in case of comparisons between the mean scores of the two groups. Graphs were done for data visualization using Microsoft Excel. The P-value of $\leq 0.05$ indicates a significant result while $\mathrm{P}$-value of $>0.05$ indicates a non-significant result

\section{Results}

Table (1) Number and Percentage Distribution of The Studied Nurses According to Their socio-demographic data (n= 58).

\begin{tabular}{|c|c|c|c|c|c|c|}
\hline \multirow[t]{2}{*}{ Personal data } & \multicolumn{2}{|c|}{$\begin{array}{c}\text { MUH } \\
(n=29)\end{array}$} & \multicolumn{2}{|c|}{$\begin{array}{c}\text { MGH } \\
(n=29) \\
\end{array}$} & \multicolumn{2}{|c|}{$\begin{array}{c}\text { Total } \\
(n=58)\end{array}$} \\
\hline & No. & $\%$ & No. & $\%$ & No. & $\%$ \\
\hline \multicolumn{7}{|l|}{ Marital status } \\
\hline Single & 6 & 20.7 & 8 & 27.6 & 14 & 24.1 \\
\hline Married & 20 & 69.0 & 18 & 62.1 & 38 & 65.5 \\
\hline Divorced & 3 & 10.3 & 3 & 10.3 & 6 & 10.3 \\
\hline \multicolumn{7}{|l|}{ Age/ years } \\
\hline Less than 20 & 6 & 20.7 & 1 & 3.4 & 7 & 12.1 \\
\hline $20-<30$ & 16 & 55.2 & 23 & 79.3 & 39 & 67.2 \\
\hline $30-40$ & 7 & 24.1 & 5 & 17.2 & 12 & 20.7 \\
\hline Mean \pm SD & \multicolumn{2}{|c|}{$25.4 \pm 6.0$} & \multicolumn{2}{|c|}{$25.7 \pm 5.3$} & & \\
\hline \multicolumn{7}{|l|}{ Educational level } \\
\hline Secondary nursing school & 11 & 37.9 & 6 & 20.7 & 17 & 29.3 \\
\hline Health institute & 13 & 44.8 & 11 & 37.9 & 24 & 41.4 \\
\hline B.Sc & 5 & 17.2 & 8 & 27.6 & 13 & 22.4 \\
\hline Master & 0 & .0 & 4 & 13.8 & 4 & 6.9 \\
\hline Years of experience & & & & & & \\
\hline
\end{tabular}




\begin{tabular}{|c|c|c|c|c|c|c|}
\hline \multirow[t]{2}{*}{ Personal data } & \multicolumn{2}{|c|}{$\begin{array}{c}\text { MUH } \\
(n=29)\end{array}$} & \multicolumn{2}{|c|}{$\begin{array}{c}\text { MGH } \\
(n=29)\end{array}$} & \multicolumn{2}{|c|}{$\begin{array}{c}\text { Total } \\
(n=58)\end{array}$} \\
\hline & No. & $\%$ & No. & $\%$ & No. & $\%$ \\
\hline Less than 5 years & 8 & 27.6 & 16 & 55.2 & 24 & 41.4 \\
\hline $5-<10$ & 12 & 41.4 & 6 & 20.7 & 18 & 31.0 \\
\hline $10-<15$ & 9 & 31.0 & 7 & 24.1 & 16 & 27.6 \\
\hline Mean \pm SD & \multicolumn{2}{|c|}{$6.2 \pm 3.9$} & \multicolumn{2}{|c|}{$6.4 \pm 4.0$} & & \\
\hline \multicolumn{7}{|l|}{ Attendance previous training } \\
\hline Yes & 14 & 48.3 & 9 & 31.0 & 23 & 39.7 \\
\hline No & 15 & 51.7 & 20 & 69.0 & 35 & 60.3 \\
\hline
\end{tabular}

Table (1) shows that $69.0 \%$ of the studied nurses in MUH and $62.1 \%$ of them in MGH were married. Regarding the age group from $20-<30$ the table shows that $55.2 \%, 79.3 \%$ of nurses in MUH, and MGH with mean \pm SD $25.4 \pm 6.0$ and $25.7 \pm 5.3$ years respectively. As the educational level, $44.8 \%$ and $37.9 \%$ of the studied nurses in MUH and MGH are technical institute nurses. Less than half $41.4 \%$ of nurses in MUH had experience from $5<10$ years while $55.2 \%$ of them in MGH had experienced less than 5 years. In addition, $51.7 \%$ of nurses in MUH and $69.0 \%$ of them in MGH didn't attend previous training about intravenous therapy.

Table (2): Relation Between Studied Nurses in Minia University Hospital (MUH) and Minia General Hospital (MGH) According to Their Total and Subtotal Knowledge Regarding Intravenous Therapy (n= 58).

\begin{tabular}{|c|c|c|c|c|c|c|c|c|}
\hline \multirow[t]{2}{*}{ Total knowledge levels } & \multicolumn{2}{|c|}{$\begin{array}{c}\text { MUH } \\
(n=29)\end{array}$} & \multicolumn{2}{|c|}{$\begin{array}{c}\text { MGH } \\
(n=29)\end{array}$} & \multicolumn{2}{|c|}{$\begin{array}{c}\text { Total } \\
(n=58)\end{array}$} & \multirow[t]{2}{*}{$\mathbf{X}^{2}$} & \multirow[t]{2}{*}{ P-valu e } \\
\hline & No. & $\%$ & No. & $\%$ & No. & $\%$ & & \\
\hline General knowledge & & & & & & & \multirow{4}{*}{5.195} & \multirow{4}{*}{$.05^{*}$} \\
\hline Very good & 15 & 51.7 & 7 & 24.1 & 22 & 37.9 & & \\
\hline Good & 10 & 34.5 & 18 & 62.1 & 28 & 48.3 & & \\
\hline Poor & 4 & 13.8 & 4 & 13.8 & 8 & 13.8 & & \\
\hline \multicolumn{9}{|l|}{ Preparation for cannulation } \\
\hline Very good & 10 & 34.5 & 5 & 17.2 & 15 & 25.9 & & \\
\hline Good & 14 & 48.3 & 12 & 41.4 & 26 & 44.8 & \multirow{2}{*}{4.703} & \multirow{2}{*}{$.05^{*}$} \\
\hline Poor & 5 & 17.2 & 12 & 41.4 & 17 & 29.3 & & \\
\hline \multicolumn{9}{|l|}{ During cannulation } \\
\hline Very good & 18 & 62.1 & 8 & 27.6 & 26 & 44.8 & & \\
\hline Good & 9 & 31.0 & 19 & 65.5 & 28 & 48.3 & \multirow[b]{2}{*}{7.418} & \multirow[b]{2}{*}{$.025^{*}$} \\
\hline Poor & 2 & 6.9 & 2 & 6.9 & 4 & 6.9 & & \\
\hline \multicolumn{9}{|l|}{ After cannulation } \\
\hline Very good & 11 & 37.9 & 6 & 20.7 & 17 & 29.3 & & \\
\hline Good & 13 & 44.8 & 6 & 20.7 & 19 & 32.8 & \multirow[b]{2}{*}{10.595} & \multirow[b]{2}{*}{$.005 * *$} \\
\hline Poor & 5 & 17.2 & 17 & 58.6 & 22 & 37.9 & & \\
\hline \multicolumn{9}{|c|}{ Prevention and Complications of Intravenous Therapy } \\
\hline Very good & 19 & 65.5 & 11 & 37.9 & 30 & 51.7 & \multirow[b]{2}{*}{4.419} & \multirow[b]{2}{*}{$.036^{*}$} \\
\hline Good & 10 & 34.5 & 18 & 62.1 & 28 & 48.3 & & \\
\hline
\end{tabular}

**Highly statistical significance differences

Table (2): shows that $51.7 \%$ of nurses in MUH and $24.1 \%$ of nurses in MGH nurses had poor general knowledge regarding intravenous therapy, $34.5 \%$ of nurses in MUH and 17.2\% of nurses in MGH nurses had poor knowledge about how to prepare for cannulation, $62.1 \%$ of nurses in MUH and $27.6 \%$ of nurses in MGH nurses had poor knowledge related to cannulation, $37.9 \%$ of nurses in MUH and 20.7\% of nurses in MGH nurses had poor knowledge about steps after cannulation and $65.5 \%$ of nurses in MUH and $37.9 \%$ of nurses in MGH nurses poor in how to prevent complications of intravenous therapy with statistical significance differences P-value $.05, .05, .025, .005, .036$ respectively.

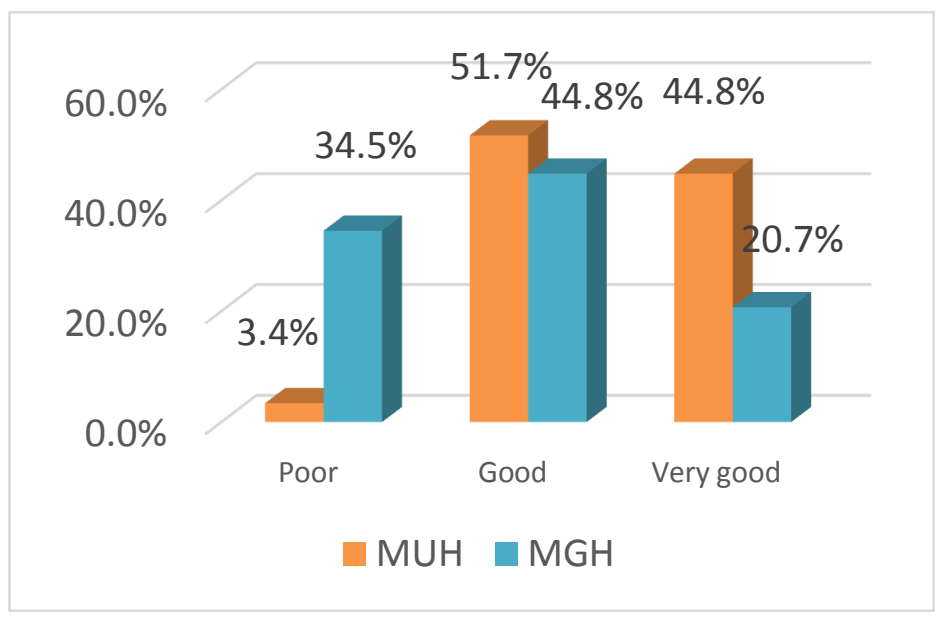

Figure (1): Between the Studied Nurses in Minia University Hospital (MUH) and Minia General Hospital (MGH) According to Their total Knowledge Regarding Intravenous Therapy $(n=58)$. 
Figure (1): illustrates that 3.4\% of nurses in MUH compared to $34.5 \%$ of them in MGH had poor knowledge regarding intravenous therapy with highly statistical significance differences P-value .006

Table (3): Relation Between Studied Nurses in Minia University Hospital (MUH) and Minia General Hospital (MGH) According to Their Practice Regarding Correctly performance $(n=58)$.

\begin{tabular}{|c|c|c|c|c|c|c|c|c|}
\hline \multirow[b]{2}{*}{ Items } & \multicolumn{2}{|c|}{$\begin{array}{c}\text { MUH } \\
(n=29)\end{array}$} & \multicolumn{2}{|c|}{$\begin{array}{c}\text { MGH } \\
(n=29)\end{array}$} & \multicolumn{2}{|c|}{$\begin{array}{c}\text { Total } \\
(n=58)\end{array}$} & \multirow{2}{*}{$\begin{array}{l}X^{2} / \text { Fisher } \\
\text { test }\end{array}$} & \multirow[t]{2}{*}{ P-value } \\
\hline & No. & $\%$ & No. & $\%$ & No. & $\%$ & & \\
\hline 1. Infection control & 3 & 10.3 & 8 & 27.6 & 11 & 19.0 & 2.831 & .243 \\
\hline 2. $\quad$ Hand washing & 3 & 10.3 & 3 & 10.3 & 6 & 10.3 & .719 & .698 \\
\hline 3. $\quad$ PPE (gown \& gloves) & 23 & 79.3 & 15 & 51.7 & 38 & 65.5 & 4.884 & .087 \\
\hline 4. I.V cannulation & 4 & 13.8 & 4 & 13.8 & 8 & 13.8 & 8.420 & $.015 *$ \\
\hline 5. $\quad$ I.V fluid & 15 & 51.7 & 8 & 27.6 & 23 & 39.7 & 3.551 & .169 \\
\hline 6. $\quad$ Blood products & 16 & 55.2 & 14 & 48.3 & 30 & 51.7 & 2.333 & .311 \\
\hline 7. Flushing of PIVC's & 12 & 41.4 & 9 & 31.0 & 21 & 36.2 & 2.518 & .284 \\
\hline 8. $\quad$ Fluid Considerations via Peripheral IV line & 9 & 31.0 & 7 & 24.1 & 16 & 27.6 & .404 & .817 \\
\hline $\begin{array}{l}\text { 9. Change of PIVC dressing and securement of } \\
\text { cannula }\end{array}$ & 18 & 62.1 & 12 & 41.4 & 30 & 51.7 & 3.771 & .152 \\
\hline 10. Management of I.V therapy complications & 21 & 72.4 & 15 & 51.7 & 36 & 62.1 & 2.933 & .231 \\
\hline
\end{tabular}

* Statistically significance differences $\quad * *$ Highly statistical significance differences

Table (3) presents that, $10.3 \%$ of studied nurses in MUH and 27.6\% of studied nurses in MGH applied infection control during I.V preparation. $10.3 \%$ of studied nurses in MUH and 10.3\% of nurses in MGH wash hands before I.V preparation. $79.3 \%$, $51.7 \%$ of studied nurses in MUH, and MGH applied PPE. 13.8\%, 13.8\% of studied nurses in MUH, and MGH applied I.V cannulation with statistically significant differences which P-value 0.015 .

$51.7 \%, 27.6 \%$ of studied nurses in MUH, and MGH administered I.V fluid correctly. $55.2 \%$ of studied nurses in MUH and $48.3 \%$ of nurses in MGH administered blood products correctly. 41.4\%, 31.0\% of studied nurses in MUH, and MGH flushed of PIVC's. $31.0 \%$ of studied nurses in MUH $24.1 \%$ of nurses in MGH done completely fluid considerations via Peripheral IV line. $62.1 \%, 41.4 \%$ of studied nurses in MUH and MGH changed of PIVC dressing and securement of cannula correctly and $72.4 \%$ of studied nurses in MUH and $51.7 \%$ of nurses in MGH managed of I.V therapy complications

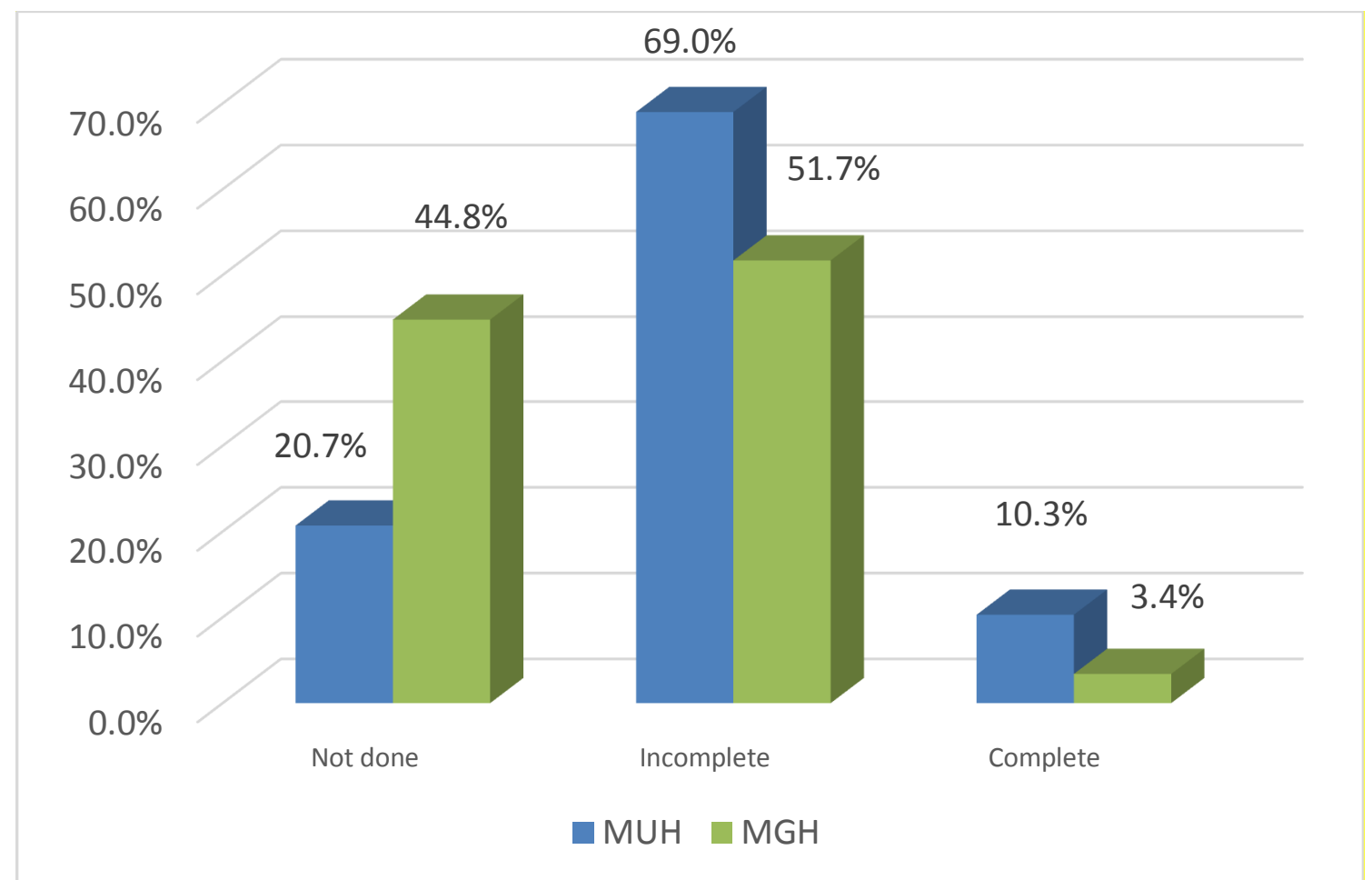

Figure (2): Comparison Between the Studied Nurses in Minia University Hospital (MUH) and Minia General Hospital (MGH) According to Their Total Practice Levels Regarding Intravenous Therapy $(\mathbf{n}=58)$.

Figure (2): illustrates that $69.0 \%$ of nurses in $\mathrm{MUH}$ and $51.7 \%$ of them in $\mathrm{MGH}$ had incomplete practice regarding intravenous therapy with no statistical significance differences P-value .117 
Minia Scientific Nursing Journal (Print - ISSN 2537-012X) (Online - ISSN 2785-9797) Vol. (8) No. (1) December 2020

Table (4): Relation Between the Studied Nurses in Minia University Hospital (MUH) and Minia General Hospital (MGH)According to Their Attitude Regarding Intravenous Therapy in $(n=58)$.

\begin{tabular}{|c|c|c|c|c|c|c|c|c|}
\hline \multirow{3}{*}{ Attitude } & \multicolumn{2}{|c|}{ MUH $(n=29)$} & \multicolumn{2}{|c|}{ MGH $(n=29)$} & \multicolumn{2}{|c|}{ Total $(n=58)$} & \multirow[t]{3}{*}{$\mathrm{X}^{2} /$ fisher } & \multirow[t]{3}{*}{ P-value } \\
\hline & Agree & Disagree & Agree & Disagree & Agree & Disagree & & \\
\hline & No. (\%) & No. $(\%)$ & No. (\%) & No. $(\%)$ & No. $(\%)$ & No. $(\%)$ & & \\
\hline $\begin{array}{l}\text { 1-Explaining the patient's nursing } \\
\text { procedure is the first step in introducing } \\
\text { the peripheral vein line? }\end{array}$ & $26(89.7)$ & $3(10.3)$ & $28(96.6)$ & $1(3.4)$ & $54(93.1)$ & $4(6.9)$ & 1.074 & .30 \\
\hline $\begin{array}{l}\text { 2- Wearing gloves is the first step in } \\
\text { cannula preparation. }\end{array}$ & $20(69.0)$ & $9(31.0)$ & $21(72.4)$ & $8(27.6)$ & $41(70.7)$ & $17(29.3)$ & .083 & .773 \\
\hline $\begin{array}{l}\text { 3- When preparing to insert the needle } \\
\text { into the skin, should the cross out be } \\
\text { down? }\end{array}$ & $16(55.2)$ & $13(44.8)$ & $9(31.0)$ & $20(69.0)$ & $25(43.1)$ & $33(56.9)$ & 3.445 & .063 \\
\hline $\begin{array}{l}\text { 4- If you tried to enter the cannula and } \\
\text { were not sure of the appropriate place, } \\
\text { would you remove the catheter and try } \\
\text { again? }\end{array}$ & $21(71.4)$ & $8(27.6)$ & $17(58.6)$ & $12(41.4)$ & $38(65.5)$ & $20(34.5)$ & 1.221 & .269 \\
\hline $\begin{array}{l}\text { 5- After two failed attempts to enter IV, } \\
\text { the best thing you can do is continue to } \\
\text { try until you get the vein? }\end{array}$ & $14(48.3)$ & $15(51.7)$ & $13(44.8)$ & $16(55.2)$ & $27(46.6)$ & $31(53.4)$ & .069 & .792 \\
\hline $\begin{array}{l}\text { 7- The most important step when } \\
\text { stopping intravenous therapy is } \\
\text { documenting the date and time and those } \\
\text { professionals who removed cannula from } \\
\text { the patient? }\end{array}$ & $24(82.8)$ & $5(17.2)$ & $23(79.3)$ & $6(20.7)$ & $47(81.0)$ & $11(19.0)$ & .112 & .738 \\
\hline $\begin{array}{l}\text { It is not necessary to wear gloves when } \\
\text { stopping IV because there is no risk of } \\
\text { exposure to blood or body fluids? }\end{array}$ & $22(75.9)$ & $7(24.1)$ & $11(37.9)$ & $18(62.1)$ & $33(56.9)$ & $25(43.1)$ & 8.507 & $.004 * *$ \\
\hline $\begin{array}{l}\text { 9- By maintaining sterilization, can acute } \\
\text { IV complications be prevented? }\end{array}$ & $23(79.3)$ & $6(20.7)$ & $21(72.4)$ & $8(27.6)$ & $44(75.9)$ & $14(24.1)$ & .377 & .539 \\
\hline $\begin{array}{l}\text { 10- The intravenous cannula must be } \\
\text { removed according to the hospital's } \\
\text { policy without regard to any patient- } \\
\text { related reasons }\end{array}$ & $12(41.4)$ & $17(58.6)$ & $14(48.3)$ & $15(51.7)$ & $26(44.8)$ & $32(55.2)$ & .279 & .597 \\
\hline
\end{tabular}

* Statistically significance differences $\quad * *$ highly statistical significance differences

Table (4): shows that, there were no statistically significant differences between nurses who are working in Minia University Hospital (MUH) and those who are working in Minia General Hospital (MGH) regarding their Attitude about Intravenous Therapy except statement about "not necessary to wear gloves in stops I.V therapy" about $75.9 \%$ of nurses who are working in Minia University Hospital (MUH) compared to $37.9 \%$ of them in Minia General Hospital (MGH) said that they agree about this statement with statistically significant differences which P-value .004

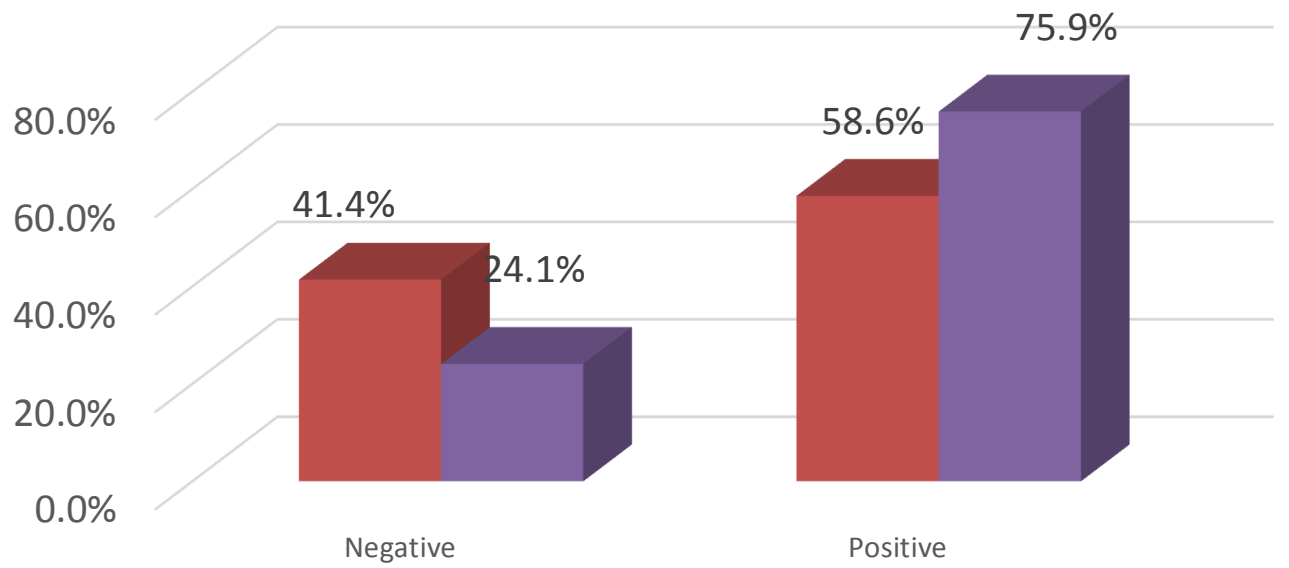

$\mathrm{MUH} \square \mathrm{MGH}$

Figure (3): Comparison Between the Studied Nurses in Minia University Hospital (MUH) and Minia General Hospital (MGH) According to Their Total Attitude Levels Regarding Intravenous Therapy $(n=58)$.

Figure (3): illustrates that more than three quarters of nurses in Minia general hospital had positive attitude regarding intravenous therapy with statistically significant difference which P-value 0.04 . 
Minia Scientific Nursing Journal (Print - ISSN 2537-012X) (Online - ISSN 2785-9797) Vol. (8) No. (1) December 2020

Table (5): Relation between Personal Data of The Studied Nurses with Their Total Knowledge Levels Regarding Intravenous Therapy in Minia University Hospital (MUH) and Minia General Hospital (MGH) (n= 58).

\begin{tabular}{|c|c|c|c|c|c|c|c|c|}
\hline \multirow[b]{4}{*}{ Personal data } & \multicolumn{6}{|c|}{$\begin{array}{r}\text { Total knowledge levels } \\
\end{array}$} & \multirow{4}{*}{$\begin{array}{l}\mathrm{X}^{2} / \text { Fisher } \\
\text { test }\end{array}$} & \multirow{4}{*}{$P$ - value } \\
\hline & \multicolumn{3}{|c|}{ MUH $(n=29)$} & \multicolumn{3}{|c|}{ MGH (n= 29) } & & \\
\hline & Very good & Good & Poor & Very good & Good & Poor & & \\
\hline & No.(\%) & No. $(\%)$ & No. $(\%)$ & No.(\%) & No. $(\%)$ & No. $(\%)$ & & \\
\hline \multicolumn{9}{|l|}{ Marital status } \\
\hline Single & $4(66.7)$ & $2(33.3)$ & $0(.0)$ & $2(25.0)$ & $5(62.5)$ & $1(12.5)$ & \multirow{3}{*}{3.266} & \multirow{3}{*}{.514} \\
\hline Married & $6(30.0)$ & $13(65.0)$ & $1(5.0)$ & $4(22.2)$ & $6(33.3)$ & $8(44.4)$ & & \\
\hline Divorced & $3(100.0)$ & $0(.0)$ & $0(.0)$ & $0(.0)$ & $2(66.7)$ & $1(33.3)$ & & \\
\hline Fisher (P - value) & \multicolumn{3}{|c|}{$6.732(.151)$} & \multicolumn{3}{|c|}{$3.760(.439)$} & & \\
\hline \multicolumn{9}{|l|}{ Age/ years } \\
\hline$<20$ & $4(66.7)$ & $2(33.3)$ & $0(.0)$ & $0(.0)$ & $1(100.0)$ & $0(.0)$ & \multirow{3}{*}{11.458} & \multirow{3}{*}{$.02 *$} \\
\hline $20-<30$ & $7(43.8)$ & $8(50.0)$ & $1(6.3)$ & $6(26.1)$ & $7(30.4)$ & $10(43.5)$ & & \\
\hline $30-40$ & $2(28.6)$ & $5(71.4)$ & $0(.0)$ & $0(.0)$ & $5(100.0)$ & $0(.0)$ & & \\
\hline Fisher (P - value) & \multicolumn{3}{|c|}{$2.795(.593)$} & \multicolumn{3}{|c|}{$9.311(.054)$} & & \\
\hline \multicolumn{9}{|l|}{ Education } \\
\hline $\begin{array}{l}\text { Secondary nursing } \\
\text { school }\end{array}$ & $8(72.7)$ & $3(27.3)$ & $0(.0)$ & $2(33.3)$ & $4(66.7)$ & $0(.0)$ & \multirow{4}{*}{16.563} & \multirow{4}{*}{$.011^{*}$} \\
\hline Health institute & $5(38.5)$ & $8(61.5)$ & $0(.0)$ & $3(27.3)$ & $4(36.4)$ & $4(36.4)$ & & \\
\hline B.Sc & $0(.0)$ & $4(80.0)$ & $1(20.0)$ & $1(12.5)$ & $2(25.0)$ & $5(62.5)$ & & \\
\hline Master & $0(.0)$ & $0(.0)$ & $0(.0)$ & $0(.0)$ & $3(75.0)$ & $1(25.0)$ & & \\
\hline Fisher (P - value) & \multicolumn{3}{|c|}{$11.355(.023 *)$} & \multicolumn{3}{|c|}{$8.115(.230)$} & & \\
\hline \multicolumn{9}{|l|}{ Years of experience } \\
\hline Less than 5 years & $4(50.0)$ & $3(37.5)$ & $1(12.5)$ & $4(25.0)$ & $5(31.3)$ & $7(43.8)$ & \multirow{3}{*}{16.379} & \multirow{3}{*}{$.003 * *$} \\
\hline $5-<10$ & $7(58.3)$ & $5(41.7)$ & $0(.0)$ & $2(33.3)$ & $1(16.7)$ & $3(50.0)$ & & \\
\hline $10-<15$ & $2(22.2)$ & $7(77.8)$ & $0(.0)$ & $0(.0)$ & $7(100.0)$ & $0(.0)$ & & \\
\hline Fisher (P - value) & \multicolumn{3}{|c|}{$5.916(.206)$} & \multicolumn{3}{|c|}{$11.760(.019 *)$} & & \\
\hline \multicolumn{9}{|l|}{$\begin{array}{l}\text { Attendance previous } \\
\text { training }\end{array}$} \\
\hline Yes & $5(33.3)$ & $9(60.0)$ & $1(6.7)$ & $5(25.0)$ & $8(40.0)$ & $7(35.0)$ & \multirow{2}{*}{1.179} & \multirow{2}{*}{.555} \\
\hline No & $8(57.1)$ & $6(42.9)$ & $0(.0)$ & $1(11.1)$ & $5(55.6)$ & $3(33.3)$ & & \\
\hline Fisher (P - value) & \multicolumn{3}{|c|}{$2.261(.323)$} & & $19(.632)$ & & & \\
\hline
\end{tabular}

* Statistically significance differences $\quad * *$ Highly statistical significance differences

Table (5): presents that, $6.3 \%$ of nurses aged between 20 - 30 years in Minia University Hospital and $43.5 \%$ of nurses aged between 20 - 30 years in Minia General Hospital had very good knowledge regarding intravenous therapy with statistically significance differences which p - value .02 and 20.0\% of bachelor nurses in Minia University Hospital and $62.5 \%$ of bachelor nurses in Minia General Hospital had very good knowledge regarding intravenous therapy with statistically significance differences which $\mathrm{p}-$ value .01. Also, $12.5 \%$ of nurses had experience less than 5 years in Minia University Hospital and 43.8\% of nurses had experience less than 5 years in Minia General Hospital had very good knowledge regarding intravenous therapy with statistically significance differences which $\mathrm{p}$ - value .003 .

Table (6): Relation between Personal Data of The Studied Nurses with Their Total Practice Levels Regarding Intravenous Therapy in Minia University Hospital (MUH) and Minia General Hospital (MGH) (n= 58).

\begin{tabular}{|c|c|c|c|c|c|c|c|c|}
\hline \multirow{4}{*}{ Personal data } & \multicolumn{6}{|c|}{ Total practice levels } & \multirow{4}{*}{$\begin{array}{l}\mathrm{X}^{2} / \text { Fisher } \\
\text { test }\end{array}$} & \multirow{4}{*}{$P$ - value } \\
\hline & \multicolumn{3}{|c|}{ MUH $(n=29)$} & \multicolumn{3}{|c|}{ MGH $(n=29)$} & & \\
\hline & Not done & Incomplete & Complete & Not done & Incomplete & Complete & & \\
\hline & No. $(\%)$ & $\begin{array}{l}\text { No. } \\
(\%)\end{array}$ & $\begin{array}{l}\text { No. } \\
(\%)\end{array}$ & No. (\%) & $\begin{array}{l}\text { No. } \\
(\%)\end{array}$ & $\begin{array}{l}\text { No. } \\
(\%)\end{array}$ & & \\
\hline \multicolumn{9}{|l|}{ Marital status } \\
\hline Single & $0(.0)$ & $6(100.0)$ & $0(.0)$ & $2(25.0)$ & $6(75.0)$ & $0(.0)$ & \multirow[t]{3}{*}{11.784} & \multirow[t]{3}{*}{$.019^{*}$} \\
\hline Married & $6(30.0)$ & $11(55.0)$ & $3(15.0)$ & $11(61.1)$ & $6(33.3)$ & $1(5.6)$ & & \\
\hline Divorced & $0(.0)$ & $3(100.0)$ & $0(.0)$ & $0(.0)$ & $3(100.0)$ & $0(.0)$ & & \\
\hline Fisher (P - value) & \multicolumn{3}{|c|}{$5.873(.209)$} & \multicolumn{3}{|c|}{$7.089(.131)$} & & \\
\hline \multicolumn{9}{|l|}{ Age/ years } \\
\hline Less than 20 & $0(.0)$ & $6(100.0)$ & $0(.0)$ & $1(14.3)$ & $6(85.7)$ & $0(.0)$ & \multirow{3}{*}{4.512} & \multirow{3}{*}{.341} \\
\hline $20-<30$ & $3(18.8)$ & $11(68.8)$ & $2(12.5)$ & $12(52.2)$ & $11(47.8)$ & $0(.0)$ & & \\
\hline $30-40$ & $3(42.9)$ & $3(42.9)$ & $1(14.3)$ & $0(.0)$ & $4(80.0)$ & $1(20.0)$ & & \\
\hline Fisher (P - value) & \multicolumn{3}{|c|}{$5.261(.262)$} & \multicolumn{3}{|c|}{$9.355\left(.05^{*}\right)$} & & \\
\hline \multicolumn{9}{|l|}{ Education } \\
\hline Secondary nursing school & $1(9.1)$ & $10(90.9)$ & $0(.0)$ & $3(50.0)$ & $3(50.0)$ & $0(.0)$ & \multirow{5}{*}{4.754} & \multirow{5}{*}{.576} \\
\hline B.Sc & $1(20.0)$ & $4(80.0)$ & $0(.0)$ & $4(50.0)$ & $3(37.5)$ & $1(12.5)$ & & \\
\hline Master & $0(.0)$ & $0(.0)$ & $0(.0)$ & $1(25.0)$ & $3(75.0)$ & $0(.0)$ & & \\
\hline Fisher (P - value) & \multicolumn{3}{|c|}{$6.884(.142)$} & \multicolumn{3}{|c|}{$3.813(.702)$} & & \\
\hline \multicolumn{7}{|l|}{ Years of experience } & & \\
\hline Less than 5 years & $1(12.5)$ & $7(87.5)$ & $0(.0)$ & $10(62.5)$ & $6(37.5)$ & $0(.0)$ & \multirow[b]{2}{*}{13.998} & \multirow[b]{2}{*}{$.007 * *$} \\
\hline $5-<10$ & $2(16.7)$ & $10(83.3)$ & $0(.0)$ & $2(33.3)$ & $4(66.7)$ & $0(.0)$ & & \\
\hline $10-<15$ & $3(33.3)$ & $3(33.3)$ & $3(33.3)$ & $1(14.3)$ & $5(71.4)$ & $1(14.3)$ & & \\
\hline Fisher (P - value) & \multicolumn{3}{|c|}{$10.130(.038 *)$} & \multicolumn{3}{|c|}{$7.301(.121)$} & & \\
\hline
\end{tabular}


Minia Scientific Nursing Journal (Print - ISSN 2537-012X) (Online - ISSN 2785-9797) Vol. (8) No. (1) December 2020

\begin{tabular}{|c|c|c|c|c|c|c|c|c|}
\hline \multirow{4}{*}{ Personal data } & \multicolumn{6}{|c|}{ Total practice levels } & \multirow{4}{*}{$\begin{array}{c}X^{2} / \text { Fisher } \\
\text { test }\end{array}$} & \multirow{4}{*}{$P$-value } \\
\hline & \multicolumn{3}{|c|}{ MUH $(n=29)$} & \multicolumn{3}{|c|}{ MGH $(n=29)$} & & \\
\hline & Not done & Incomplete & Complete & Not done & Incomplete & Complete & & \\
\hline & No. (\%) & $\begin{array}{l}\text { No. } \\
(\%)\end{array}$ & $\begin{array}{l}\text { No. } \\
(\%)\end{array}$ & No. $(\%)$ & $\begin{array}{l}\text { No. } \\
(\%)\end{array}$ & $\begin{array}{l}\text { No. } \\
(\%)\end{array}$ & & \\
\hline \multicolumn{9}{|c|}{ Attendance previous training } \\
\hline Yes & $2(13.3)$ & $10(66.7)$ & $3(20.0)$ & $12(60.0)$ & $7(35.0)$ & $1(5.0)$ & \multirow[t]{2}{*}{6.069} & \multirow[t]{2}{*}{$.048^{*}$} \\
\hline No & $4(28.6)$ & $10(71.4)$ & $0(.0)$ & $1(11.1)$ & $8(88.9)$ & $0(.0)$ & & \\
\hline Fisher (P - value) & \multicolumn{3}{|c|}{$3.637(.162)$} & \multicolumn{3}{|c|}{$1.244 \quad 027 *)$} & 1.245 & 1.246 \\
\hline
\end{tabular}

* Statistically significance differences $\quad * *$ Highly statistical significance differences

Table (6): shows that $15.0 \%$ of married nurses in Minia University Hospital and $5.6 \%$ of married nurses in Minia General Hospital had complete practice regarding intravenous therapy with statistically significance differences which $\mathrm{p}-$ value .019 and $33.3 \%$ of nurses had experience $10-<15$ years in Minia University Hospital and $14.3 \%$ of nurses had experience $10-<15$ years in Minia General Hospital had complete practice regarding intravenous therapy with statistically significance differences which $\mathrm{p}-$ value .007 . Also, $20.0 \%$ of nurses in Minia University Hospital who attended previous training and $5.0 \%$ of nurses in Minia General Hospital who attended previous training had complete practice regarding intravenous therapy with statistically significance differences which $\mathrm{p}$ - value. 048 .

Table (7) Relation between Personal Data of The Studied Nurses with Their Total Attitude Levels Regarding Intravenous Therapy in Minia University Hospital (MUH) and Minia General Hospital (MGH) (n= 58).

\begin{tabular}{|c|c|c|c|c|c|c|}
\hline \multirow{4}{*}{ Personal data } & \multicolumn{4}{|c|}{$\begin{array}{c}\text { Total attitude levels } \\
\end{array}$} & \multirow{4}{*}{$\mathrm{X}^{2} /$ Fisher test } & \multirow{4}{*}{$P$-value } \\
\hline & \multicolumn{2}{|c|}{ MUH $(n=29)$} & \multicolumn{2}{|c|}{ MGH $(n=29)$} & & \\
\hline & $\begin{array}{c}\text { Negative } \\
(n=12)\end{array}$ & $\begin{array}{c}\text { Positive } \\
(n=17)\end{array}$ & Negative $(n=7)$ & $\begin{array}{c}\text { Positive } \\
(n=22)\end{array}$ & & \\
\hline & No. $(\%)$ & No. $(\%)$ & No. $(\%)$ & No. $(\%)$ & & \\
\hline \multicolumn{7}{|l|}{ Marital status } \\
\hline Single & $4(33.3)$ & $2(11.8)$ & $2(28.6)$ & $6(27.3)$ & \multirow[t]{3}{*}{2.174} & \multirow[t]{3}{*}{.337} \\
\hline Married & $6(50.0)$ & $14(82.3)$ & $4(57.1)$ & $14(63.6)$ & & \\
\hline Divorced & $2(16.7)$ & $1(5.9)$ & $1(14.3)$ & $2(9.1)$ & & \\
\hline Fisher (P - value) & \multicolumn{2}{|c|}{$3.440(.179)$} & \multicolumn{2}{|c|}{$.178(.915)$} & & \\
\hline \multicolumn{7}{|l|}{ Age/ years } \\
\hline Less than 20 & $6(50.0)$ & $0(.0)$ & $0(.0)$ & $1(4.5)$ & \multirow[t]{3}{*}{10.690} & \multirow[t]{3}{*}{$.005 * *$} \\
\hline $20-<30$ & $6(50.0)$ & $10(58.8)$ & $5(71.4)$ & $18(81.8)$ & & \\
\hline $30-40$ & $0(.0)$ & $7(41.2)$ & $2(28.6)$ & $3(13.7)$ & & \\
\hline Fisher (P - value) & \multicolumn{2}{|c|}{$13.540(.001 * *)$} & \multicolumn{2}{|c|}{$1.077(.583)$} & & \\
\hline \multicolumn{7}{|l|}{ Educational level } \\
\hline Secondary nursing school & $1(8.3)$ & $4(23.5)$ & $1(14.2)$ & $7(31.8)$ & \multirow{4}{*}{9.114} & \multirow{4}{*}{$.028 *$} \\
\hline Health institute & $4(33.3)$ & $9(52.9)$ & $3(42.9)$ & $8(36.4)$ & & \\
\hline B.Sc & $7(58.4)$ & $4(23.6)$ & $3(42.9)$ & $3(13.6)$ & & \\
\hline Master & $0(.0)$ & $0(.0)$ & $0(.0)$ & $4(18.2)$ & & \\
\hline Fisher (P - value) & \multicolumn{2}{|c|}{$3.792(.150)$} & \multicolumn{2}{|c|}{$4.115(.249)$} & & \\
\hline \multicolumn{7}{|l|}{ Years of experience } \\
\hline Less than 5 years & $6(50.0)$ & $2(11.8)$ & $4(57.1)$ & $12(54.6)$ & \multirow{4}{*}{4.153} & \multirow{4}{*}{.125} \\
\hline $5-<10$ & $6(50.0)$ & $6(35.3)$ & $1(14.3)$ & $5(22.7)$ & & \\
\hline $10-<15$ & $0(.0)$ & $9(52.9)$ & $2(28.6)$ & $5(22.7)$ & & \\
\hline Fisher (P - value) & \multicolumn{2}{|c|}{$10.449\left(.005^{* *}\right)$} & \multicolumn{2}{|c|}{$.265(.876)$} & & \\
\hline \multicolumn{7}{|l|}{ Attendance previous training } \\
\hline Yes & $8(66.7)$ & $7(41.2)$ & $5(71.4)$ & $15(68.2)$ & \multirow[t]{2}{*}{.770} & \multirow[t]{2}{*}{.380} \\
\hline No & $4(33.3)$ & $10(58.8)$ & $2(28.6)$ & $7(31.8)$ & & \\
\hline Fisher (P - value) & \multicolumn{2}{|c|}{$1.830(.176)$} & \multicolumn{2}{|c|}{$.026(.872)$} & & \\
\hline
\end{tabular}

* Statistically significance differences $\quad * *$ Highly statistical significance differences

Table (7): presents that, 58.8\% of nurses aged 20 - 30 years in Minia University Hospital and $81.8 \%$ of them in Minia General Hospital had positive attitude regarding intravenous therapy with statistically significance differences which $\mathrm{p}-$ value .005 and $52.9 \%$ of health institute nurses in Minia University Hospital and 36.4\% of them in Minia General Hospital had positive attitude regarding intravenous therapy with statistically significance differences which $\mathrm{p}$ - value .028 .

Table (8): Correlation between selected personal Data of the Studied Nurses with Their Total Knowledge, Practice, Attitude Levels Regarding Intravenous Therapy in Minia University Hospital (MUH) and Minia General Hospital (MGH)

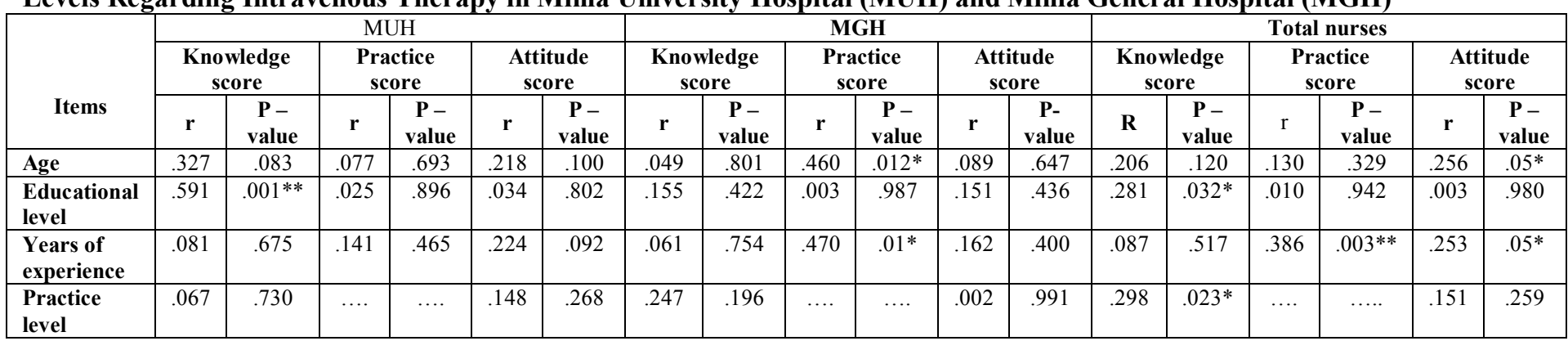


Table (8): presents that, fair positive association between nurses knowledge score with their educational level and practice level ( $\mathrm{r}=.281 ; \mathrm{p}$ - value $0.032 \& \mathrm{r}=.298 ; \mathrm{p}$ - value 0.023 respectively), fair positive association between practice score with years of nurses experience $(r=.386 ; \mathrm{p}$ - value 0.003$)$ and fair positive association between nurses attitude with their age and years of experience $(\mathrm{r}=.256 ; \mathrm{p}-$ value $0.05, \mathrm{r}=.253 ; \mathrm{p}-$ value 0.05$)$.

\section{Discussion}

Most of the interventions and prevention strategies such as insertion, monitoring and assessing peripheral venous catheter (PVC) sites are part of routine nursing care. The nurse should have accurate knowledge of the preparation and administration of the IV Infusion and IV device. In addition, they should also know about the prevention, treatment, and management of local and systematic complications supported by dynamic evidence-based practice guidelines. One of the major risks for phlebitis incidence is due to the placement and maintenance of PVC by insufficiently trained staff (Mohammed \& Ahmed, 2017).

Regarding the age of the studied nurses, the current study revealed that more than two-thirds of the studied nurses their age in between $20-<30$ in MUH and MGH with mean \pm SD $25.7 \pm 5.1$ years. This result comes in the line with (Ouda, Mahmoud, Kafi, and Soliman, 2019) that studied "Nurses' Knowledge and Practices Regarding Peripheral Intravenous Cannulation and Blood Sampling in Pediatric Health Care Settings " and reported that the most of the studied sample was in between 18:30 years and with mean \pm SD 24.44 \pm 4.30 years. This result comes in accordance with (Milutinović, Simin, \& Zec, 2015) who studied " Risk factor for phlebitis: a questionnaire study of nurses' perception" and reported that the mean age of the nurses was $33.2(\mathrm{SD}=7.2)$ years of age. The youngest nurse was 20 years and the oldest was 56 years old. This result due to the nurses' age after graduation ranged from 20- 23 years.

Regarding educational level, the current study illustrated that less than one-third of studied nurses had secondary nursing school. This result contradicted with (Milutinović et al., 2015) who founded that more than half of the nurses $(61.8 \%)$ had completed secondary medical school, while more than one-third of them graduated from college or university, and three (2.9\%) had a master's degree in nursing.

Regarding previous experience and training the current study showed that less than half of the studied nurses had experienced less than 5 years and slightly less than twothirds of the studied nurses attend previous training. This result differs from (Ouda, et al., 2019) who mentioned that less than half of the studied nurses had experienced less than 3 years and less than one quarter had experience less than 5 years. In addition, Ouda, et al., (2019) mentioned that more than half of the studied nurses had previous training. This result may be due to the working in the emergency and pediatric department difficult work so many nurses transferred to another department

Regarding the relation between studied nurses in Minia university hospital (MUH) and Minia general hospital (MGH) according to their general knowledge, the present study showed that more than one-third of MUH nurses compared to less than two-third of MUH nurses had good knowledge. this result was confirmed by (Qamar, Muhammad, Kousar, Waqas, \& Gilani, 2017) who studied " Nurses Knowledge and Practices towards Care and Maintenance of Peripheral Intravenous Cannulation in Services Hospital Lahore, Pakistan" and reported that the most of nurses had good knowledge regarding care and peripheral IV cannula safe usage.

Regarding Preparation for Cannulation, the present study illustrated that less than half of MUH nurses and MGH nurses had good knowledge about preparation for cannulation. This result agree with (Osti et al., 2019) who mentioned that the majority of the studied sample had proper knowledge regarding intravenous cannulation that includes the cannula size, site, duration, proper steps during cannulation, and sign and symptom of infection and proper measure to prevent infection. This result may be due to less than one-third of studied nurses had secondary nursing school and they don't take sufficient clinical training

Regarding the studied nurses' knowledge during cannulation, the current study showed that less than two-thirds of the studied nurses in MUH had good knowledge about the steps during cannulation and more than two-third of MUH nurses had good knowledge during cannulation. This result didn't come in the line with (Osti et al., 2019) who stated that the majority of the studied sample was doing correct practices regarding intravenous cannulation. This result due to less than half of the studied nurses had experienced less than 5 years.

Regarding the relation between studied nurses in Minia university hospital (MUH) and Minia general hospital $(\mathrm{MGH})$ according to their knowledge after cannulation, the current study showed that less than half of the studied nurses in MUH had good knowledge and more than half of MUH nurses had very good knowledge. This result comes in to agree with (Ouda et al., 2019) who studied " Nurses' Knowledge and Practices Regarding Peripheral Intravenous Cannulation and Blood Sampling in Pediatric Health Care Settings" and revealed that half of the studied nurses had satisfactory knowledge regarding peripheral intravenous cannulation and blood sampling. This result comes in to agree with (Lamsal \& Shrestha, 2019) who studied "nurses' knowledge and practice regarding intravenous therapy in a teaching hospital, Bhagalpur" and reported that the level of knowledge was found inadequate and level of practice was found unsatisfactory on IV therapy.

Regarding the relation between studied nurses in Minia university hospital (MUH) and Minia general hospital (MGH) according to their knowledge regarding prevention and complications of intravenous therapy, the current study showed that more than two-thirds of MUH nurses had good knowledge and less than two-third of MGH had very good knowledge regarding prevention and complications of intravenous therapy with statistical significance differences Pvalue .036 This result was supported by (Osti et al., 2019) who mentioned that the respondents had knowledge that thrombophlebitis and infection are the common complications of IV cannulation and the most of them were aware of the influences of environmental cleanliness on IV site infection. But this result comes inconsistent with (Milutinović et al., 2015) who studied "Risk factor for phlebitis: a questionnaire study of nurses' perception" and reported that nurses recognized some factors that may reduce the incidence of phlebitis; however, more than half of the nurses were unaware 
that the material and diameter of the cannula can affect the incidence rate of phlebitis.

Regarding the relation between studied nurses in Minia University Hospital (MUH) and Minia General Hospital (MGH) according to their practice regarding perform correctly infection control precautions, the current study showed that the most of the studied nurses in MUH and MGH didn't apply infection control during I.V preparation. This result comes inconsistent with (El-Greeb et al., 2018) who studied the Nurses' Compliance with Infection Control Standard Precautions at Outpatient Clinics of Urology and Nephrology Center - Mansura University" and reported that there was a satisfactory score level in relation to handling sharps instruments, wearing gloves and following infection control precaution.

Regarding the relation Between Studied Nurses in Minia University Hospital (MUH) and Minia General Hospital (MGH) According to Their Practice Regarding Perform Correctly Hand Washing Procedure, the current study showed that the majority of the studied nurses didn't apply hand washing before I.V preparation. This result was supported by (Jemal, 2018) who studied "knowledge and practices of handwashing among health professionals in dubti referral hospital, dubti, afar, northeast Ethiopia" and reported that the majority of the studied sample was knowledgeable and more than one third were not knowledgeable. However, the majority of health professionals had poor practice and less than half of them had a good practice of handwashing. Also, this result was lower than the result of a study done at Shonen Gibe Hospital, Southeast Ethiopia, in which the majority of the studied sample had good knowledge and less than fifth had poor knowledge (Alemu et al., 2015). This result may be due to nurses believes not important to wash their hands before the procedure but it's important after doing the procedure

Regarding the relation between studied nurses in Minia university hospital (MUH) and Minia general hospital (MGH) according to their practice regarding performing correctly personal protective equipment, The current study showed that the most of studied nurses in MUH and more than half of MGH nurses applied PPE. This result comes inconsistent with (Powers, Armellino, Dolansky, \& Fitzpatrick, 2016) who studied " Factors influencing nurse compliance with Standard Precautions" a reported that most of the studied sample had poor compliance with standard precautions.

Regarding the relation Between Studied Nurses in Minia University Hospital (MUH) and Minia General Hospital (MGH) According to Their Practice Regarding Perform Correctly Intravenous Cannulation, the current study showed that the majority of nurses in MUH and MGH didn't follow the correct steps of cannulation. this result was come inconsistently with (Morgaonkar et al., 2017) who studied" Educational intervention to improve intravenous cannulation skills in pediatric nurses using low-fidelity simulation: Indian experience" and reported that most of the studied sample perform correctly intravenous cannulation.

Regarding the Preparation of Intravenous Fluids, the current study showed that more than half of studied nurses in MUH and less than one-third MGH prepared and administered I.V fluid correctly. This result comes in the line with (Qamar et al., 2017) who studied " Assess Nurses Knowledge and Practices towards Care and Maintenance of Peripheral Intravenous Cannulation in Services Hospital Lahore,
Pakistan" and reported that the more than have of the studied nurses had poor practices.

Regarding Correctly Administration of Blood Products, the present study showed that more than half of studied nurses in MUH and less than half of nurses in $\mathrm{MGH}$ administered blood products correctly. This result comes in the line with (Flood \& Higbie, 2016) who studied "A comparative assessment of nursing students' cognitive knowledge of blood transfusion using lecture and simulation" and reported that less than half of the studied nurse administered blood products correctly. Also, this result was confirmed by (Frazier, Higgins, Bugajski, Jones, \& Brown, 2017) who studied " Adverse Reactions to Transfusion of Blood Products and Best Practices for Prevention" and reported that less than two-thirds of the studied sample follow the guideline in the administration of blood product.

Regarding the Flushing of PIVC's, the present study illustrated that less than half of studied nurses in MUH and MGH flushed of PIVC's. this result didn't come in accordance with (Graveto, Costa, de Almeida Osório, Cosme, \& Parreira, 2019) who studied "Nurses' peripheral intravenous catheter-related practices: a descriptive study" and reported that more than half of the studied sample make flushing of PIVC's.

Regarding Correctly IV Fluid Considerations via Peripheral IV line, the current study showed that less than one-third of studied nurses in MUH and less than one-quarter of nurses in MGH done completely fluid considerations via Peripheral IV line. These result results come in accordance with (Thabet Ahmed, Mohammad, Ez El-Deen, \& Sayed, 2013) who studied "Effect of a designed nursing protocol on nurse's knowledge and practice regarding Intravenous Therapy" and reported that the most of the studied nurses had poor practices regarding I.V fluids. This result was confirmed by (Qamar et al., 2017) who reported that less than half of the studied nurses had good practices regarding administration I.V fluids.

Regarding the change of PIVC dressing and securement of the cannula, the current study showed that less than two-thirds of studied nurses in MUH and less than half in MGH changed of PIVC dressing and securement of cannula correctly. This result comes inconsistent with (Ouda et al., 2019) who studied "nurses' knowledge and practices regarding peripheral intravenous cannulation and blood sampling in the pediatric health care setting and mentioned that the majority of the studied nurse had unsatisfactory practices.

Regarding correctly management of I.V therapy complications the current study showed that, less than three quadrants of studied nurses in MUH and more than have of nurses in MGH managed of I.V therapy complications. This result was confirmed by (Punjot, Mathew, Suseel, \& Thomas, 2018) who studied " A study to assess the effectiveness of infusion experts on the nursing interventions of peripheral intravascular devices among patients admitted to a tertiary care hospital of the city" and reported that the nurses become aware of measures that prevent I.V therapy complications.

Regarding the total practice levels regarding intravenous therapy, the present study showed that less than two-third had incomplete practices level This result didn't come in the line with (Othman \& Ahmed, 2019) who studied "nurses Knowledge, Attitude and Practice Concerning Fluid Therapy in Children Hospital in Erbil City, Kurdistan Region Iraq" and reported that less than two-thirds of the studied 
sample had fair practices. This result comes inconsistent with (Arbaee, 2016) who reported that the majority of the studied nurses followed the correct practice of care and maintenance of IV cannula.

Regarding the relation between studied nurses in Minia university hospital (MUH) and Minia general hospital $(\mathrm{MGH})$ according to their opinion regarding their roles during and after intravenous therapy, the current study showed that less than one-quarter of the studied nurses in MGH and MUH had correct pinion regarding their roles during and after intravenous therapy. This result comes in the line with (ElGreeb et al., 2018) who stated that all studied nurses showed a good level of knowledge related to the definition of infection control and standard precautions, the cycle of infection, aim and components of standard precautions of infection control standards and post-action of the needle stick. Generally, the total knowledge categories showed a good level of studied nurses.

Regarding nurses' attitude about intravenous therapy, the current study showed that more than one third of nurses worked in Minia University Hospital (MUH) had negative attitude about Intravenous Therapy. This result comes in the line with (Othman \& Ahmed, 2019) who studied "nurses Knowledge, Attitude and Practice Concerning Fluid Therapy in Children Hospital in Erbil City, Kurdistan Region Iraq' and reported that more than half of the studied nurses had negative attitude regarding intravenous therapy and recommended to pay attention to nurses' knowledge, attitude, and practices through an educational program.

Regarding the correlation between selected personal data of the studied nurses with their total knowledge, practice, attitude levels regarding intravenous therapy in Minia University Hospital (MUH) and Minia General Hospital, the present study mentioned that there was a fair positive association between nurses knowledge score with their educational level and practice level ( $\mathrm{r}=.281$; $\mathrm{p}$-value $0.032 \&$ $\mathrm{r}=.298$; $\mathrm{p}$-value 0.023 respectively), fair positive association between practice score with years of nurses experience $(\mathrm{r}=$ .386; p-value 0.003) and fair positive association between nurses attitude with their age and years of experience $(r=.256$; $\mathrm{p}$-value $0.05, \mathrm{r}=.253$; $\mathrm{p}$-value 0.05$)$. this result comes in the line with (Abd-Alfatah et al., 2013) who reported that there is no statistically significant difference between the nurses' knowledge and their practice regarding nursing care of children undergoing hemodialysis. This result in the same line with the evidence high nurses educational had more knowledge and practices in dealing with illness child.

Regarding the relation between personal data of the studied nurses with their total knowledge levels regarding intravenous therapy in Minia university hospital (MUH) and Minia general hospital, the current study illustrated that there were statistically significance differences between the total level of nurses' knowledge and educational level and Years of experience. This result come in agree with (Mohammed, Sultan, \& Abdulhassan, 2017) who reported that there were statistical differences between socio-demographic characteristics and total nurse's knowledge score. Also this result was confirmed by (Galvão, Serique, Santos, \& Nogueira, 2017) who reported that there were statistical significance differences between the total knowledge score and year of experience.

This result come in agree with (Abd-Alfatah, Ahmad, \& Mohamed, 2013) who reported that there is statistical significance difference between age and level of knowledge for studied nurses $p$ value (0.044) and There is statistical significance difference between years of experience and level of knowledge $p$ value (0.005). In contrast with (As, 2011) who studied "Knowledge and performance of health team about infection control in the neonatal intensive care units at Assiut and El Minia university hospitals" and stated that the nurses who aged less than 20 years had excellent score of knowledge.

Regarding the relation between personal data of the studied nurses with their total practice levels regarding intravenous therapy in Minia university hospital (MUH) and Minia General Hospital (MGH), The current study showed that there were statistically significance differences between the total level of practices and the socio-demographic characteristics. This result come in agree with (Abd-Alfatah et al., 2013) who reported that, there is statistical significance difference between age of studied nurses and level of practice with $P$ value $(0.001)$ and there was statistical significance difference between having training courses and level of practice. This result may be due to slightly less than two third of the studied nurses attend previous training.

Regarding the relation between personal data of the studied nurses with their total attitude levels regarding intravenous therapy in Minia University Hospital (MUH) and Minia General Hospital (MGH), the current study stated that, there were statistically significance differences between nurse's attitude and their age and educational level.

This result come in agree with (Carr et al., 2011) who studied "Interns' attitudes to IV cannulation" and reported that there were statistically significance differences between nurse's attitude and the socio-demographic characteristics (Hossain, Hasan, \& Haque, 2016) who studied "Assessment of the level of knowledge and practice on intravenous canalization among staff nurses of selected tertiary care hospital in Dhaka city" reported the same result.

\section{Conclusion}

Based on the result of the present study one third of nurses worked in Minia General Hospital had complete knowledge regarding intravenous therapy than a few of nurses worked in Minia University hospital, studied nurses in Minia University hospital had more practice and positive attitude than nurses in Minia General Hospital regarding intravenous therapy.

\section{Recommendations}

Based on the results of the present study are:

The educational program should be applied and repeated every 3 months in the same study settings and adopted in other similar settings with necessary modifications, the provision of continuing education programs is suggested regularly to refresh and update the knowledge of nurses, as well as to reinforce appropriate practices in pediatric units related to intravenous therapy with continuous supervision.

\section{References}

(1) Abd-Alfatah, A., Ahmad, A., \& Mohamed, F. (2013). Assessment of Nurses' Knowledge and Practice Related to Nursing Care of Children Undergoing Hemodialysis at Assiut City. Unpublished Master Thesis, Department of Medical-Surgical Nursing Science. Faculty of Nursing, Assuit University.

(2) Alemu, B. S., Bezune, A. D., Joseph, J., Gebru, A. A., Ayene, Y. Y., \& Tamene, B. A. (2015). Knowledge and practices of hand washing and glove utilization among the health care providers of shonen gibe hospital, South West Ethiopia. Science, 3(3), 391-397. 
and treating infiltration. Retrieved from http://ceu.cinahl.com/ course/500012702

(3) Arbaee, I. (2016). Nurse's knowledge and practice towards care and maintenance of. Qualitative Research, 1(3), 385-405.

(4) Arbaee, I. (2016). Nurse's knowledge and practice towards care and maintenance of. Qualitative Research, 1(3), 385-405.

(5) As, A. (2011). Knowledge and performance of health team about infection control in the neonatal intensive care units at Assiut and El Minia university hospitals. Unpublished doctoral thesis. Faculty of Nursing, Pediatric nursing department, Assiut university

(6) Carr, P. J., Glynn, R. W., Dineen, B., Devitt, D., Flaherty, G., Kropmans, T. J., \& Kerin, M. (2011). Interns' attitudes to IV cannulation: a KAP study. British Journal of Nursing, 20(4), S15S20.

(7) Center for Disease Control (CDC) (2013). Morbidity and Mortality Weekly Report.Guidelines for the Prevention of Intravascular Catheter-Related Infections. Retrieved 2013-03.

(8) De Lima Jacinto, A., Avelar, A., \& Pereira, M., (2011). Predisposing factors for infiltration in children submitted to peripheral venous catheterization: Journal of infusion nursing: the official publication of the Infusion Nurses Society 34(6):391-8 .

(9) El-Greeb, H. E`.Amel, I., Hussien, M., \& Samia, M. (2018). Assessment of nurses' compliance with infection control standard precautions at outpatient clinics of Urology and Nephrology Center-Mansur University. J Nurs Health Sci, 7(3), 54-59 .

(10) Flippo, P. L., \& Lee, J., (2011). Clinical evaluation of the Sorbaview Shield securement device used on peripheral intravenous catheters in the acute care setting: The journal of the association for vascular access, 16(2), 100-102.

(11) Flood, L. S., \& Higbie, J. (2016). A comparative assessment of nursing students' cognitive knowledge of blood transfusion using lecture and simulation. Nurse education in practice, 16(1), 8-13

(12) Frazier, S. K., Higgins, J., Bugajski, A., Jones, A. R., \& Brown, M. R. (2017). Adverse reactions to transfusion of blood products and best practices for prevention. Critical Care Nursing Clinics, 29(3), 271-290 .

(13) Galvão, N. S., Serique, M. A. B., Santos, V. L. C. d. G., \& Nogueira, P. C. (2017). Knowledge of the nursing team on pressure ulcer prevention. Revista Brasileira de Enfermagem, 70(2), 294-300.

(14) Graveto, J. M .G. N., Costa, F. J. G., de Almeida Osório, N. I., Cosme, A. S. T. C., \& Parreira, P. M. D. (2019). Nurses' peripheral intravenous catheter-related practices: a descriptive study. Revista de Enfermagem Referência, 4(21), 111-120 .

(15) Hossain, A., Hasan, M \&,.Haque, M. (2016). Assessment of the level of knowledge and practice on intravenous cannulization among staff nurses of selected tertiary care hospital in Dhaka City. MOJ Public Health, 4(5), 00095.

(16) Hoste, E. A., Maitland, K., Brudney, C. S., Mehta, R., Vincent, J.L., Yates, D., . . . Shaw, A. (2014). Four phases of intravenous fluid therapy: a conceptual model. British journal of anesthesia, 113(5), 740-747.

(17) Jemal, S. (2018). Knowledge and Practices of Hand Washing among Health Professionals in Dubti Referral Hospital, Dubti, Afar, Northeast Ethiopia. Advances in preventive medicine, 2018.

(18) Lamsal, S., \& Shrestha, R. (2019). Nurses' knowledge and practice regarding intravenous therapy in a teaching hospital, Bharatpur. Journal of Chitwan Medical College, 9(1), 13-19.

(19) Milutinović, D., Simin, D., \& Zec, D. (2015). Risk factor for phlebitis: A questionnaire study of nurses' perception. Revista Latino-Americana de enfermagem, 23(4), 677-684 .
(20) Mohammed, A. Q., Sultan, M. A., \& Abdulhassan, S. A. (2017). Assessment of Nurses' Knowledge Concerning Protein Energy Malnutrition for Children under Age Five Years at Medical Wards in Baghdad City. Mosul Journal of Nursing, 5(2), 87-91 .

(21) Mohammed, SI., \& Ahmed, HM. (2017). Nurses Competence Regarding Vascular Access Care in Dongola Renal Center-2017. Published master thesis, Shendi University,

(22) Morgaonkar, V. A., Shah, B. V., Nimbalkar, S. M., Phatak, A. G., Patel, D. V., \& Nimbalkar, A. S. (2017). An educational intervention to improve intravenous cannulation skills in pediatric nurses using low-fidelity simulation: Indian experience. BMJ pediatrics open, 1 (1

(23) Osti, C., Khadka, M., Wosti, D., Gurung, G., \& Zhao, Q. (2019). Knowledge and practice towards care and maintenance of peripheral intravenous cannula among nurses in Chitwan Medical College Teaching Hospital, Nepal. Nursing Open, 6(3), 10061012 .

(24) Othman, N. R., \& Ahmed, A. A. (2019). Nurses Knowledge, Attitude, and Practice Concerning Fluid Therapy in Children Hospital in Erbil City, Kurdistan Region Iraq. Indian Journal of Forensic Medicine \& Toxicology, 13(4), 658-662.

(25) Othman, N. R., \& Ahmed, A. A. (2019). Nurses Knowledge, Attitude, and Practice Concerning Fluid Therapy in Children Hospital in Erbil City, Kurdistan Region Iraq. Indian Journal of Forensic Medicine \& Toxicology, 13(4), 658-662 .

(26) Ouda, W. E.-S., \& Mahmoud, M. F., and Soliman, H. H., (2019). Nurses' Knowledge and Practices Regarding Peripheral Intravenous Cannulation and Blood Sampling in Pediatric Health Care Settings. Port Said Scientific Journal of Nursing, 6(3), 50-67 .

(27) Palomo, T., Fassier, F., Ouellet, J., Sato, A., Montpetit, K., Glorieux, F. H., \& Rauch, F. (2015). Intravenous bisphosphonate therapy of young children with osteogenesis imperfecta: skeletal findings during follow up throughout the growing years. Journal of Bone and Mineral Research, 30(12), 2150-2157.

(28) Patricia AS., and Anne GP. ,(2008). Canadian Fundamentals of Nursing. E book, 4th edition Elseier publication .

(29) Powers, D., Armellino, D., Dolansky, M., \& Fitzpatrick, J. (2016). Factors influencing nurse compliance with Standard Precautions. American journal of infection control, 44(1), 4-7 .

(30) Punjot, P., Mathew, J., Suseel, S., \& Thomas, V. (2018). International Journal of Nursing Research (IJNR .(

(31) Qamar, Z., Muhammad, A., Kousar, R., Waqas, A., \& Gilani, S. A. (2017). Assess nurses' knowledge and practice towards care and maintenance of peripheral intravenous cannulation in services hospital Lohore, Pakistan. Saudi J. Med. Pharm. Sci, 3(6B), 608614 .

(32) Terese M.V and Marlene M. (2010). Core curriculum for neonatal intensive care nursing - E- book. 4th edition. Elsevier Publication. Section two: cornerstones of clinical practice.

(33) Thabet Ahmed, M. A., Mohammad, Z. A., Ez El-Deen, M. E., \& Sayed, S. Y. (2013). Effect of a designed nursing protocol on nurse's knowledge and practice regarding Intravenous Therapy. Assiut Scientific Nursing Journal, 1(1), 130-138 .

(34) Walsh, K. \& Schad, T. (2012). Nursing practice \& skill intravenous therapy: Preventing

(35) Zhang, L., Cao, S., Marsh, N., Ray-Barruel, G., Flynn, J., Larsen, E., \& Rickard, C. M. (2016). Infection risks associated with peripheral vascular catheters. Journal of infection prevention, 17(5), 207-213. 